\title{
Accuracy of morphological diagnosis of lung cancer in a department of respiratory medicine
}

\author{
MARTIN D CLEE, HELEN LD DUGUID,* DAVID JM SINCLAIR $\dagger$ \\ From the Department of Respiratory Medicine, King's Cross Hospital, Dundee and the ${ }^{*}$ Cytology Unit, \\ Department of Pathology, Royal Infirmary, Dundee
}

SUMMARY In view of the importance of determination of cell type in patients with bronchial carcinoma who are to be given chemotherapy a series of 140 histologically proved cases was analysed to assess the accuracy of pretreatment diagnosis by cytology and bronchial biopsy. Final histological diagnosis was made after thoracotomy (131 cases) or necropsy ( 9 cases).

Before treatment, malignancy was diagnosed in $71 \%$ of cases with $91 \%$ accuracy in cell typing. Diagnostic yield was greatest in squamous carcinoma ( $81 \%$ ) and least with adenocarcinoma $(50 \%)$. Large-celled and small-celled anaplastic carcinomas gave yields of $61 \%$ and $68 \%$ respectively. Accuracy of cell typing was high (90-97\%) except for large-celled anaplastic carcinoma (71\%).

All diagnostic methods were not employed in every case. In patients supplying samples the diagnosis was made by sputum cytology in $57 \%$, by rigid bronchoscopy cytology in $57 \%$, by fibreoptic bronchoscopy cytology in $71 \%$ and biopsy in $53 \%$.

Causes of diagnostic failures and possible means of increasing accuracy of pretreatment diagnosis were discussed.

During recent years there have been significant advances in both the diagnosis and treatment of primary bronchial carcinoma. Fibreoptic bronchoscopy was developed in Japan in 1964 and introduced in America in $1969^{1}$ and Britain in the 1970 s. ${ }^{2}$ It is a safe technique with few complications and can be performed quickly with minimal discomfort to the patient. Direct examination of the entire tracheobronchial tree to the level of the subsegmental bronchi is possible allowing biopsy of tumours inaccessible at rigid bronchoscopy. ${ }^{3}$ Beyond the range of the instrument a diagnosis may be made by brush or transbronchial biopsy under fluoroscopic control $^{1}$ and needle biopsy can be used for more peripheral tumours. ${ }^{4}$

Accurate morphological diagnosis of bronchial carcinoma before treatment is now possible in all cases and is increasingly important since it allows accurate evaluation of the various drug regimens of cytotoxic treatment in small-celled carcinoma and avoids subjecting patients with non-responsive, non-small-celled anaplastic carcinoma to drugs causing serious morbidity.

In this area the Department of Respiratory

$\nmid$ Present address: Poole Hospital, Nunthorpe, Cleveland.

Accepted for publication 15 July 1981
Medicine undertakes the investigation of cases of possible bronchial carcinoma and the management of cytotoxic treatment. Cases requiring operation are referred elsewhere.

The purpose of this study is to review the yield of our pretreatment morphological diagnosis of malignancy and accuracy of cell typing and to investigate the problems involved in obtaining high diagnostic yield and accuracy.

\section{Patients and methods}

Case notes and laboratory reports of all patients admitted to the Chest Unit between 1976 and 1979 with a diagnosis of primary bronchial carcinoma confirmed histologically at thoracotomy (131) or necropsy (9) were studied.

Final histology was defined as the predominant cell type noted in the excised lung tumours or at necropsy. The tumours had been classified as epidermoid $73(52 \%)$; small-celled anaplastic $22(16 \%)$; largecelled anaplastic or poorly differentiated (tumour type not specified) $23(16 \%)$; adenocarcinoma 18 $(13 \%)$; and combined epidermoid and adenocarcinoma $4(3 \%)$. 
The diagnostic yield of each initial (pretreatment) investigation was defined as the percentage of patients submitting specimens in which malignant cells were identified.

The diagnostic accuracy was defined as the percentage agreement between the cell type obtained at initial investigation and the histological confirmation.

\section{SPUTUM}

A minimum of three specimens was obtained from each patient, those containing alveolar macrophages being accepted as satisfactory for examination. Special attention was directed to obtaining satisfactory specimens; all patients received physiotherapy and were issued with specific written instructions which were reinforced and supervised by the nursing staff. Since we have long recognised that better sputum specimens may be obtained after bronchoscopy the majority of the sputa submitted were first morning specimens on three consecutive days after bronchoscopy. The specimens were scrutinised at ward level. If obviously unsatisfactory they were discarded and further samples obtained unless the patient's cough was non-productive when all specimens obtained were sent for examination.

\section{BRONCHOSCOPIC SPECIMENS}

Distinction was made between patients who had rigid and fibreoptic bronchoscopy. A tumour was defined as visible only if endobronchial tumour tissue was seen and in these cases brushings were taken from the abnormal area; where there was no visible lesion, brushings were taken from the appropriate lobar or segmental bronchus indicated by the radiological positions on posteroanterior and lateral chest $x$-rays. Biopsies were taken only when tumour tissue was suspected at fibreoptic bronchoscopy. The rigid bronchoscope was employed during the earlier part of the study when only a limited number of biopsy specimens were obtained. Whenever possible the hospital MLSO was present at the bronchoscopy session. He prepared the specimens for histological and cytological examination and informed the bronchoscopist if samples were macroscopically adequate.

\section{BRONCHIAL BRUSH SPECIMENS}

Smears from each brushing were spread over an area of $1 \mathrm{~cm}^{2}$ on two previously labelled glass slides and immediately placed in cytological fixative (Carbowax $30 \mathrm{~g}$, glacial acetic acid $2 \mathrm{ml}, 95 \%$ alcohol to one litre). Bronchial aspirate was collected in a Vygon mucus extractor from which suitable portions were removed with an orange stick, spread between two slides and immediately fixed in cytological fixative.
BRONCHIAL BIOPSY

Usually several biopsies were taken. The biopsy material was washed from the biopsy forceps with sterile tissue culture fluid into a centrifuge tube containing formol saline. After the final biopsy the forceps were agitated in the fixative to remove small tissue particles.

\section{METHOD OF REPORTING}

In order to ensure uniformity in nomenclature of initial and final reports all specimens in which the original diagnosis had been undifferentiated or poorly differentiated carcinoma were reviewed without knowledge of the final tumour histology.

In 34 of 38 cytology specimens it was possible to make a more specific diagnosis of tumour type including eight cases of small-celled anaplastic carcinoma but in seven biopsy specimens due to the small amount of tissue and crush artefacts more precise specification was not possible. These specimens were therefore classified in the large-celled anaplastic group.

False-positive cytology reports in experienced hands should be less than $1 \%$ of the total positive cases. "Suspicious" reports are therefore given when the appearances do not conform to the recognised cellular patterns of the various types of malignancy or if necrosis or degeneration precludes a more accurate diagnosis. In this study reports "suspicious of malignancy" were not included in the analysis.

\section{Results}

Table 1 analyses the diagnostic accuracy of the various types of investigation. The percentage yield for sputum of $57 \%$ was similar to that of other series. ${ }^{5} 6$ With sputum there is a high degree of cell type accuracy $(90 \%)$ and like others we have found that tumour cells which exfoliate in sputum are often more differentiated and therefore easier to classify.? The cytological yield for fibreoptic bronchoscopy $(71 \%)$ was greater than that for rigid bronchoscopy $(57 \%)$ but accuracy of cell type diagnosis $(91 \%)$ was greater in rigid bronchoscopy. This was probably due to the larger volume of specimens obtained. Both yield $(53 \%)$ and cell type accuracy $(76 \%)$ of biopsy specimens obtained at fibreoptic bronchoscopy were poor. However, as the forceps are very small, it is possible to miss tumour tissue, the sample being taken from overlying or adjacent norma lor abnormal epithelium. ${ }^{8}$ Accurate tumour typing is difficult when the biopsy specimen is tiny and subject to crush artefact. 89

In Table 2 the accuracy of cell type diagnosis at the various initial investigations was compared with the final histological findings. 
Table 1 Diagnostic accuracy of various types of investigation

\begin{tabular}{|c|c|c|c|c|}
\hline & Sputum & $\begin{array}{l}\text { Bronchial brushings } \\
\text { and aspirations } \\
\text { (rigid) }\end{array}$ & $\begin{array}{l}\text { Bronchial brushings } \\
\text { and aspirations } \\
\text { (fibreoptic) }\end{array}$ & $\begin{array}{l}\text { Bronchial biopsy } \\
\text { (fibreoptic) }\end{array}$ \\
\hline Patients supplying samples & 107 & 58 & 70 & 55 \\
\hline Malignancy diagnosed & 61 & 33 & 50 & 29 \\
\hline Percentage yield $(\%)$ & 57 & 57 & 71 & 53 \\
\hline Accurate cell type diagnosed & 55 & 30 & 42 & 22 \\
\hline Percentage accuracy $(\%)$ & 90 & 91 & 84 & 76 \\
\hline
\end{tabular}

Table 2 Preoperative diagnosis of cell type compared with tumour histology at thoracotomy or necropsy

\begin{tabular}{|c|c|c|c|c|c|c|}
\hline \multirow{2}{*}{$\frac{\text { Investigation }}{\text { Preoperative cell type }}$} & \multirow[t]{2}{*}{$n$} & \multicolumn{5}{|c|}{ Tumour type (thoracotomy or necropsy) } \\
\hline & & Epidermoid & $\begin{array}{l}\text { Small-celled } \\
\text { anaplastic }\end{array}$ & $\begin{array}{l}\text { Large-celled } \\
\text { anaplastic }\end{array}$ & Adenocarcinoma & $\begin{array}{l}\text { Epidermoid and } \\
\text { adenocarcinoma }\end{array}$ \\
\hline \multicolumn{7}{|l|}{ Sputum } \\
\hline Epidermoid & 44 & $39(88 \%)$ & 1 & 2 & & $2(5 \%)$ \\
\hline Small-celled anaplastic & 8 & & $8(100 \%)$ & & & \\
\hline Large-celled anaplastic & 4 & & & $4(100 \%)$ & & \\
\hline Adenocarcinoma & 5 & & & & $5(100 \%)$ & \\
\hline \multicolumn{7}{|c|}{$\begin{array}{l}\text { Rigid bronchoscopy aspirations } \\
\text { and brushings }\end{array}$} \\
\hline Epidermoid & 23 & $21(91 \%)$ & & 2 & & \\
\hline Small-celled anaplastic & 4 & & $4(100 \%)$ & & & \\
\hline Large-celled anaplastic & 5 & 1 & & $4^{f}(80 \%)$ & & \\
\hline Adenocarcinoma & 1 & & & & $1(1 / 1)$ & \\
\hline \multicolumn{7}{|c|}{$\begin{array}{l}\text { Fibreoptic bronchoscopy aspirations } \\
\text { and brushings }\end{array}$} \\
\hline Epidermoid & 26 & $24(92 \%)$ & 1 & 1 & & \\
\hline Small-celled anaplastic & 8 & & $8(100 \%)$ & & & \\
\hline Large-celled anaplastic & 9 & 3 & & $5(55 \%)$ & 1 & \\
\hline Adenocarcinoma & 7 & $i$ & & & $5(71 \%)$ & $1(14 \%)$ \\
\hline \multicolumn{7}{|l|}{ Fibreoptic bronchial biopsy } \\
\hline Epidermoid & 17 & $17(100 \%)$ & & & & \\
\hline Small-celled anaplastic & 3 & & $2(67 \%)$ & & 1 & \\
\hline Large-celled anaplastic & 7 & 3 & 2 & $2(30 \%)$ & & \\
\hline Adenocarcinoma & 2 & 1 & & & $1(1 / 1)$ & \\
\hline
\end{tabular}

$\mathrm{n}=$ total number of patients producing positive samples.

With epidermoid carcinoma there was a high degree of accuracy in all methods of investigation reaching $100 \%$ in biopsy specimens. Poorly differentiated epidermoid carcinoma was diagnosed cytologically in five cases ( 7 samples) where the final diagnosis was anaplastic carcinoma (small-celled 1 case, large-celled 4 cases). In the first case the most probable explanation was the occurrence of squamous differentiation in a predominately smallcelled anaplastic carcinoma. The remaining four cases illustrate the difficulty in typing (both histologically and cytologically) of large-celled anaplastic and poorly differentiated carcinomas. Mennemeyer et $a l^{10}$ in a series of such cases verified the diagnosis by electron microscopy and found that cytology gave a more accurate diagnosis of cell type than histology.

The initial cytological and histological typing of small-celled anaplastic carcinoma and adenocarcinoma was also very accurate. Cytologically oat-celled carcinomas show characteristic cell groupings with moulding of adjacent cells. ${ }^{711}$ One adenocarcinoma was diagnosed on biopsy as small-celled anaplastic carcinoma but on review crush artefact was noted. In most adenocarcinomas tumour acini or papillary clusters can be identified. ${ }^{12}$ In two specimens (1 case) the original diagnosis was adenocarcinoma (with confirmed mucus secretion) but the final diagnosis was epidermoid carcinoma. Here the most likely diagnosis was combined epidermoid and adenocarcinoma.

Most discrepancies in tumour typing occurred when the initial diagnosis was large-celled anaplastic carcinoma and it is in this group that the accuracy of sputum $(100 \%)$ and rigid bronchoscopy cytology $(80 \%)$ was superior to fibreoptic bronchoscopy cytology $(55 \%)$ and biopsy $(30 \%)$. Tumour cells in bronchial brushings appear less mature ${ }^{6}$ than in sputum and the cells are often arranged in sheets losing their characteristic groupings. ${ }^{13}$ We have found that as fibreoptic bronchoscopy cytology specimens are scanty they must be spread and fixed very rapidly; if drying occurs before fixation, the cells flatten and appear larger, the characteristic chromatin pattern of wet-fixed preparations is lost 
and the cell type cannot be diagnosed. Accurate diagnosis in biopsy specimens was only possible in two of seven cases.

In Table 3 the yield and accuracy of diagnosis in practice are analysed. Of the 99 cases providing positive samples, 83 had positive bronchoscopic cytology either alone or with positive biopsy or sputum. In 10 cases sputum provided the only morphological evidence of malignancy and in four cases the biopsy alone was positive. Yield was highest for epidermoid carcinoma $(81 \%)$ as here tumour breakdown and exfoliation occurs readily. With small-celled carcinoma the yield was smaller $(68 \%)$. Large-celled anaplastic tumours gave a yield of $61 \%$ and the lowest yield $(50 \%)$ was obtained with adenocarcinomas which are often peripheral. In assessing the predominant cell type, the results of all initial investigations were compared and where there was a discrepancy (18 cases) the final diagnosis was made in the light of our experience. If epidermoid or adenocarcinoma was noted in an adequate biopsy, this was taken as correct but if the biopsy was inadequate or reported as containing anaplastic or poorly differentiated carcinoma, the findings in sputum, bronchial brushings and aspirations were taken as being more accurate. Taking these factors into consideration a high rate of diagnostic accuracy was achieved except in the large-celled anaplastic carcinoma group where classification by tumour histology is also difficult. ${ }^{10}$

\section{Discussion}

In view of the intensive investigation into the best treatment for small-celled anaplastic carcinoma, accurate pretreatment diagnosis is essential. The small differences likely to be detected in therapeutic trials for non-operable small-celled anaplastic carcinomas, demands a minimum of inaccurate diagnoses for inclusion of non-responsive tumours would invalidate the results. Chemotherapy has many side effects, notably nausea, vomiting, and debility. Accurate cell typing would prevent patients with non-responsive tumours entering such trials and receiving inappropriate therapy. In this study, using three types of primary investigation (sputum, bronchoscopic cytology and biopsy) 14 of 22 cases $(64 \%)$ of small-celled carcinomas were diagnosed accurately; one case was diagnosed as squamous carcinoma.

The results of fibreoptic bronchial biopsy in small-celled anaplastic carcinomas were disappointing. Eight biopsies were carried out, tumour tissue was identified in four and in only two $(25 \%)$ was the correct diagnosis made.

In experienced hands pulmonary cytology is a very reliable technique which contributes significantly to the accurate diagnosis of bronchial carcinoma. ${ }^{6}$ Although the highest percentage of positive results are obtained by a combination of biopsy and cytology using fibreoptic bronchoscopy, ${ }^{815-17}$ all diagnostic methods should be employed if maximum yield and accuracy of diagnosis is to be obtained. ${ }^{246141618}$

We intend to use several additional techniques which will improve the accuracy of pretreatment investigation.

\section{SPUTUM}

A high yield from sputum examination depends on careful instruction and supervision of the patient to ensure that material from a "deep cough" only is submitted and in the laboratory care in selecting suitable blood-stained areas or tissue fragments for spreading.

The technique of the collection and preparation of specimens can be monitored by recording the percentage of unsatisfactory samples (containing no alveolar macrophages). In 1976 at the beginning of this investigation our unsatisfactory rate was $48 \%$ but this has now been reduced to $28 \%$ which is in

Table 3 Combined yield and accuracy for all preoperative diagnostic methods

\begin{tabular}{|c|c|c|c|c|c|c|}
\hline & \multicolumn{6}{|c|}{ Tumour type (thoracotomy or necropsy) } \\
\hline & $\begin{array}{l}\text { Epidermoid } \\
73\end{array}$ & $\begin{array}{l}\text { Small-celled } \\
\text { anaplastic } \\
22\end{array}$ & $\begin{array}{l}\text { Large-celled } \\
\text { anaplastic } \\
23\end{array}$ & $\begin{array}{l}\text { Adenocarcinoma } \\
18\end{array}$ & $\begin{array}{l}\text { Epidermoid and } \\
\text { adenocarcinoma } \\
4\end{array}$ & $\begin{array}{l}\text { Total } \\
140\end{array}$ \\
\hline \multicolumn{7}{|l|}{ Yield of positive findings } \\
\hline Sputum alone & 5 & 1 & 2 & 1 & 1 & 10 \\
\hline Biopsy alone & 3 & 1 & - & - & - & 4 \\
\hline Sputum + biopsy & 1 & - & - & 1 & - & 2 \\
\hline Aspiration and brushings alone & 11 & 4 & 6 & 3 & - & 24 \\
\hline +sputum & 22 & 6 & 4 & 3 & 1 & 36 \\
\hline +biopsy & 6 & 2 & 1 & 1 & - & 10 \\
\hline +sputum and biopsy & 11 & 1 & 1 & - & - & 13 \\
\hline Combined yield & $59(81 \%)$ & $15(68 \%)$ & $14(61 \%)$ & $9(50 \%)$ & $2(50 \%)$ & $99(71 \%)$ \\
\hline $\begin{array}{l}\text { Accuracy } \\
\text { (Predominant tumour type) }\end{array}$ & $57(97 \%)$ & $14(93 \%)$ & $10(71 \%)$ & $8(90 \%)$ & $1(1 / 2)$ & $90(91 \%)$ \\
\hline
\end{tabular}


keeping with figures quoted from a general hospital ${ }^{5}$ but lower figures $(9 \%)$ from a chest unit have been obtained. ${ }^{5}$

The preparation of smears of sputum is a timeconsuming and meticulous procedure and should not be delegated to a junior member of the laboratory staff; ${ }^{14}$ in a busy laboratory, however, this may be unavoidable. Improved results have been quoted using a homogenisation and concentration technique $^{6}$ but we have no experience of this method.

In practice sputum cytology can be expected to diagnose between 50 and $60 \%$ of an unselected series of lung cancer patients. ${ }^{56}$ Although increasing the number of satisfactory samples examined from each patient will improve the yield, the additional work makes heavy demands on highly trained staff. An additional series of sputa, therefore, should only be submitted when there is a strong clinical suspicion of malignancy and the diagnosis cannot be made by other methods. ${ }^{5} 14$

\section{FIBREOPTIC BRONCHOSCOPIC CYTOLOGY}

Samples obtained at fibreoptic bronchoscopy are the most rewarding of all methods of diagnosis. The bronchoscope is passed nasally and is not withdrawn until the procedure is completed. Aspirations and brush material must therefore be drawn along the whole length of the bronchoscope and it is possible that much of the material is lost in the interior. ${ }^{16}$ Some withdraw the bronchoscope with brush in situ after each brushing ${ }^{16}$ but this necessitates the insertion of the bronchoscope through an endotracheal tube which causes considerable discomfort to the patient. An alternative is to submit to the laboratory material obtained when cleaning the bronchoscope after use, mixed with an equal part of cytological fixative. When tumour tissue is not seen it has been our practice to take brushings from abnormal areas indicated by posteroanterior and lateral $x$-ray examination but an improved yield is quoted if brushings are performed under fluoroscopic control. ${ }^{18}$

\section{BRONCHIAL BIOPSY}

With biopsy, tiny specimens and crush artefacts preclude accurate diagnosis. Toothed or fenestrated forceps may give a larger biopsy and multiple biopsies at one point, thereby obtaining tissue from deeper within the tumour, may also improve the results. It has been our practice only to take biopsy specimens when there was visible evidence of tumour but in almost $50 \%$ of cases indirect evidence of tumour only is present. ${ }^{2}$ Improved results will be expected if in these cases transbronchial biopsy under fluoroscopic control is employed. 915

In the histological laboratory great care is required in the processing of tiny portions of often friable tissue. Identification of such particles in embedding wax may be difficult and it has been suggested that colouring the material by the addition of saturated aqueous solution of acid fuchsin (acid violet 19) to give a definite pink colour to the fixing fluid is extremely valuable. ${ }^{19}$ Alternatively processing may be carried out in resin and sections $(1 \mu \mathrm{m})$ cut. Precise identification of tumour type using electron microscopy is not practicable outwith research centres.

FINE NEEDLE ASPIRATION BIOPSY

We have used fine needle aspiration successfully in a few peripheral carcinomas. Here a yield of $90 \%$ has been quoted. ${ }^{4}$ With this technique there is a risk of pneumothorax, but it is rarely a serious problem.

\section{Conclusion}

A high yield and a high degree of accuracy in preoperative lung cancer diagnosis is possible outwith highly specialised units but considerable experience and meticulous attention to technique is required both clinically and in the laboratory. When malignant cells show poor differentiation it is often possible, by paying careful attention to cellular arrangement, chromatin pattern, size, number and arrangement of nucleoli and cytoplasmic detail, to give an accurate cell type diagnosis. In this way it becomes possible to improve the recruitment rate to treatment trials particularly for small-celled carcinoma of the bronchus.

We wish to thank Mr James Methven, Senior MLSO, King's Cross Hospital and Mr William Allan, Senior Chief MLSO, Cytology Unit, Dundee Royal Infirmary, who are responsible for the collection, preparation and screening of cytological specimens, and the Pathology staff of Ninewells Hospital, Dundee and Edinburgh Royal Infirmary for histological examinations.

\section{References}

${ }^{1}$ Richardson RH, Zavala DC, Mukerjee PK, Bedell GN. The use of fiberoptic bronchoscopy and brush biopsy in the diagnosis of suspected pulmonary malignancy. Am Rev Respir Dis 1974;109:63-6.

2 Macdonald JB. Fibreoptic bronchoscopy today: a review of 255 cases. Br Med J 1975; iii:753-5.

${ }^{3}$ Webb J, Clarke SW. A comparison of biopsy results using rigid and fibreoptic bronchoscopes. Br J Dis Chest 1980; 74:81-3.

${ }^{4}$ Dahlgren SE, Lind B. Comparison between diagnostic results obtained by transthoracic needle biopsy and by sputum cytology. Acta Cytol 1972;16:53-8.

${ }^{5}$ Oswald NC, Hinson KFW, Canti G, Miller AB. The diagnosis of primary lung cancer with special reference 
to sputum cytology. Thorax $1971 ; 26: 623-31$.

- Johnston WW, Frable WJ. The cytopathology of the respiratory tract: a review. Am J Pathol 1976;84:372-413.

${ }^{7}$ Bedrossian CWM, Rybka DL. Bronchial brushing during fiberoptic bronchoscopy for the cytodiagnosis of lung cancer: comparison with sputum and bronchial washings. Acta Cytol 1976;20:446-53.

${ }^{8}$ Kvale PA, Bode FR, Kini S. Diagnostic accuracy in lung cancer. Comparison of techniques used in association with flexible fiberoptic bronchoscopy. Chest 1976;69: 752-7.

9 Sackner MA. State of the art. Bronchofiberscopy. Am Rev Respir Dis 1975;111:62-88.

${ }^{10}$ Mennemeyer R, Hammar SP, Bauermeister DE, Wheelis RF, Jones HW, Bartha M. Cytologic, histologic and electron microscopic correlations in poorly differentiated primary lung carcinoma. Acta Cytol 1979:23: 297-302.

${ }^{11}$ Spriggs AI, Boddington MM. Oat-cell bronchial carcinoma. Identification of cells in pleural fluid. Acta Cytol 1976;20:525-9.

${ }^{12}$ Roger V, Nasiell M, Linden M, Enstad I. Cytologic differential diagnosis of bronchiolo-alveolar carcinoma and bronchogenic adenocarcinoma. Acta Cytol 1976; 20:303-7.

13 Bibbo M, Fennessy JJ, Lu C-T, Straus FH, Variakojis D, Wied GL. Bronchial brushing technique for the cytologic diagnosis of peripheral lung lesions: a review of
693 cases. Acta Cytol 1973;17:245-51.

${ }^{14}$ Koss LG, Melamed MR, Goodner JT. Pulmonary cytology -A brief survey of diagnostic results from 1 July 1952 until 31 December 1960. Acta Cytol 1964;8:104-13.

${ }^{15}$ Hanson RR, Zavala DC, Rhodes ML, Keim LW, Smith JD. Transbronchial biopsy via flexible fiberoptic bronchoscope: results in 164 patients. Am Rev Respir Dis 1976:114:67-72.

${ }^{16}$ Chopra SK, Genovesi MG, Simmons DH, Gothe B. Fiberoptic bronchoscopy in the diagnosis of lung cancer. Comparison of pre- and post-bronchoscopy sputa, washings, brushings and biopsies. Acta Cytol 1977;21: 524-7.

${ }^{17}$ Solomon DA, Solliday NH, Gracey DR. Cytology in fiberoptic bronchoscopy. Comparison of bronchial brushing, washing and post-bronchoscopy sputum. Chest 1974;65:616-9.

18 Erozan YS, Frost JK. Cytopathologic diagnosis of cancer in pulmonary material: A critical histopathologic correlation. Acta Cytol 1970;14:560-5.

19 Lendrum AC. On the handling of small biopsy material. Br Med J 1943;ii:644.

Requests for reprints to: Dr Helen LD Duguid, Department of Pathology, Cytology Unit, Royal Infirmary, Dundee DD1 9ND, Scotland. 